\title{
EFEKTIVITAS EM-4 DALAM MENURUNKAN KADAR COD LIMBAH CAIR BATIK CAP DI KELURAHAN SIMBANG WETAN KABUPATEN PEKALONGAN JAWA TENGAH
}

\author{
Wintah $^{1}$, Kiswanto $^{2}$, Endah Sulistiyowati ${ }^{3}$ \\ ${ }^{1}$ Wintah Fakultas Kesehatan Masyarakat Universitas Teuku Umar Meulaboh \\ ${ }^{2}$ Kiswanto Fakultas Teknik Universitas Teuku Umar Meulaboh \\ ${ }^{3}$ Fakultas Sains dan Teknologi Universitas Nahdhatul Ulama Purwokerto. \\ Korespondensi: syuga_2006@yahoo.co.id
}

\begin{abstract}
The objectives of this research are: (1) To know the effectiveness of lowering the rate of liquid waste COD stamp batik. (2) To know the most effective dose of the EM-4 in lowering the COD levels of liquid waste of stamp batik. (3) To know the day of how many EM-4 is most effective in lowering COD's liquid waste stamp batik. The study used the complete random design of the factorial pattern of dosage EM-4 $0 \mathrm{ml} / \mathrm{L}, 10 \mathrm{ml} / \mathrm{L}, 15 \mathrm{ml} / \mathrm{L}$ and prolonged incubation for 1 day, 2 days, 3 days. The Data obtained is analyzed using two-lane analysis (Two Way Anova). Based on the results of the analysis of the treatment EM-4 and the old incubation against the liquid waste stamp batikobtained the following results: At a group of doses acquired $F$ count $=4209.382>F$ table $5 \%=3.55$, then $\mathrm{HO}$ rejected or there is a real influence of various doses of EM-4 which is used against COD levels. At the time group gained $F$ count $=77.756>F$ table $5 \%=3.55$, then concluded that there is a real influence of incubation time against the rate of COD waste car stamp batik. The most effective EM-4 dosage to lower COD levels of liquid waste stamp batikis $15 \mathrm{ml} / \mathrm{l}$ which is capable of lowering COD levels by $96.24 \%$ and the most effective prolongedincubation time is the first day.
\end{abstract}

Keywords: Effectiveness, Prolonged incubation, EM-4, COD, Waste batik stamp.

\section{PENDAHULUAN}

\subsection{Latar belakang}

Perkembangan industri batik berbagai daerah membawa dampak bagi kehidupan manusia. Dampak positif misalnya menambah tingkat ekonomi dan membuka lapangan kerja. Hal ini memang diharapkan oleh manusia dalam rangka meningkatkan kualitas dan kenyamanan hidup. Dampak negatifnya, limbah batik dapat mencemari air sungai yang dapat menurunkan kualitas air, sehingga harus dapat diatasi dengan sebaik-baiknya. Apalagi di Kelurahan Simbang Wetan Kabupaten Pekalongan yang masih rendah kesadaran masyarakat tentang pengelalolaan limbah batik. Senyawa-senyawa yang terkandung dalam air limbah akan meningkatkan kandungan BOD (Biological Oxygen
Demand), COD (Chemical Oxygen Demand), TSS (Total Suspended Solid), TDS (Total Dissolved Solid), pH, nitrit, bau (Wardhana,1995). Limbah cair batik dapat diolah dengan menggunakan Effective Microorganisms-4 (EM-4). EM-4 adalah campuran mikroorganisme baik aerob maupun anaerob yang hidup bersimbiosis satu sama lain. Komposisi EM-4 terdiri dari bakteri asam laktat, ragi, Actinomycetes dan bakteri fotosintesis (Setiyani, 2000). Indriani (1999) menyatakan bahwa EM-4 memiliki manfaat banyak sekali diantaranya meningkatkan ketersediaan senyawa organik pada tanah, mempercepat pengomposan sampah organik, menghambat pertumbuhan bakteri patogen tanah, meningkatkan kualitas air pada perikanan, membersihkan air limbah, 
memperbaiki sifat biologis, kimia, dan fisik tanah,

Pada umumnya air yang telah tercemar kandungan oksigennya sangat rendah, karena oksigen yang telarut dalam air diserap oleh mikroorganisme untuk memecah atau mendegradasi bahan buangan organik, sehingga menjadi bahan yang mudah menguap (ditandai dengan bau busuk). Selain itu, bahan buangan organik juga dapat bereaksi dengan oksigen yang terlarut dalam air. Dengan melihat kandungan oksigen yang terlarut di dalam air dapat ditentukan seberapa jauh tingkat pencemaran air telah terjadi. Cara yang digunakan untuk pengukuran tingkat pencemaran dengan uji COD dan BOD (Wardhana, 1995). Berdasarkan penelitian yang telah dilakukan oleh Sri Undiyati (2003), ternyata EM-4 yang paling efektif dapat menurunkan COD limbah cair tahu adalah EM-4 dengan dosis $3 \mathrm{ml} / \mathrm{l}$ dan penelitian yang dilakukan oleh Enik Indarwati (2004), ternyata EM-4 dengan dosis EM-4 14 ml/l yang paling efektif dalam menurunkan kadar COD limbah cair batik di Kabupaten Sragen. Kelurahan Simbang Wetan merupakan sentra home industry batik di Kabupaten Pekalongan. Sebagian besar limbah home industry batik tidak diolah terlebih dahulu sebelum dibuang. Berkaitan dengan hal tersebut, peneliti tertarik untuk mengembangkan penelitian pada limbah cair Batik Cap di Kelurahan Simbang Wetan Kabupaten Pekalongan.

\subsection{Perumusan Masalah}

Apakah EM-4 dapat menurunkan kadar COD limbah cair batik cap, dosis dan hari ke berapakah EM-4 yang paling efektif dalam menurunkan COD limbah?

\subsection{Tujuan Penelitian}

Mengetahui efektivitas EM-4 dalam menurunkan kadar COD limbah cair batik cap, mengetahui dosis paling efektif dari EM-4 dan pada hari ke berapa EM-4 yang paling efektif dalam menurunkan COD limbah cair batik cap.

\section{TINJAUAN PUSTAKA}

\subsection{EM-4 (Effective Microorganisms -4)}

Setiyani (2000) menyatakan bahwa Effektive microorganisms (EM) adalah campuran dari berbagai jenis mikroorganisme baik aerob maupun anaerob yang hidup bersimbiosis satu sama lain secara artifisial. Komposisi mikroorganisme penyusun EM-4 adalah bakteri asam laktat, ragi, Actinomycetes, dan bakteri fotosintesis.

EM-4 merupakan mikroorganisme yang menguntungkan. Mikroorganisme yang dipilih untuk proses pembuatan EM-4 adalah mikroorganisme yang paling efektif dalam memfermentasi bahan organik (Meriatna et al., 2018). EM-4 memiki manfaat untuk meningkatkan unsur hara tanah, mempercepat pengomposan sampah, mempercepat pertumbuhan mikroorganisme yang menguntungkan, meningkatkan senyawa organik tanah, meningkatkan sifat biologis, kimia, dan fisik tanah (Indriani, 1999).

Prasetya (2001) menyatakan bahwa EM-4 selain bermanfaat untuk meningkatkan kualitas air, EM-4 juga bermanfaat untuk penanggulangan limbah. Pemanfaataan EM-4 yang dicampur dengan disinfektan dapat membunuh mikroorganisme dalam EM-4. EM4 tidak dapat digunakan apabila baunya tidak sedap dan warnanya sudah berubah menjadi gelap.

\subsection{Limbah Cair}

Limbah cair adalah sampah cair yang berasal dari permukiman, industri, perdagangan, perkotaan, rumah sakit, dan perkantoran (Rahmat dan Mallongi, 2018). Nasir dan Fatkhurohman (2012) menyatakan bahwa limbah hasil industri menghasilkan limbah yang rentan terhadap pencemarn lingkungan.

Yuliastuti dan Handaru (2017) menyatakan bahwa limbah sebelum dibuang seharusnya ada proses pengolahan terlebih dahulu. Proses pengolahan limbah salah satunya adalah secara kimia dengan menggunakan proses adsorbsi, koagulasi, dan flokulasi.

Pengolahan limbah harus dilakukan dari hulu sampai hilir untuk menghidari ancaman pencemaran yang luas (Xue et al., 2013). Achillas et al. (2013) menyatakan bahwa limbah yang diolah dapat memberikan manfaat secara ekonomi bagi pelaku industri. 


\subsection{Tinjauan Tentang Chemical Oxygen Demand (COD)}

Chemical Oxygen Demand (COD) adalah jumlah oksigen yang terlarut dalam mendegradasi bahan organik dalam air (Islamawati et al., 2018).

Wardana (1995), menyatakan bahwa COD atau kebutuhan oksigen kimia adalah jumlah oksigen yang diperlukan agar bahan buangan yang ada di dalam air dapat teroksidasi melalui reaksi kimia. Dalam hal ini bahan buangan organik akan dioksidasi oleh kalium bikromat menjadi gas $\mathrm{CO}_{2}$ dan $\mathrm{H}_{2} \mathrm{O}$ serta sejumlah ion krom. Kalium bikromat digunakan sebagai sumber oksigen (oxydizing agent). COD merupakan salah satu parameter untuk mengukur tingkat pencemaran di suatu badan perairan (Estikarini et a.l, 2016).

\subsection{Proses Pembuatan Batik Cap.}

Batik cap menggunakan alat khusus yaitu canting cap. Waktu pembuatan batik cap relatif lebih singkat. Batik cap biasanya menggunakan warna dasar lebih tua dibandingkan dengan batik tulis. Selain itu, batik cap memiliki bentuk disain gambar yang terlihat kaku dan biasanya tidak tembus pada bagian atas dan bawah kain (Sovia et al., 2016)

Setiawati (2004) menyatakan bahwa proses pembuatan batik cap memiliki proses pembuatan yang hampir sama dengan batik tulis. Perbedaannya pada alat yang digunakan pada proses penempelan lilin.

\subsection{Kerangka Pemikiran}

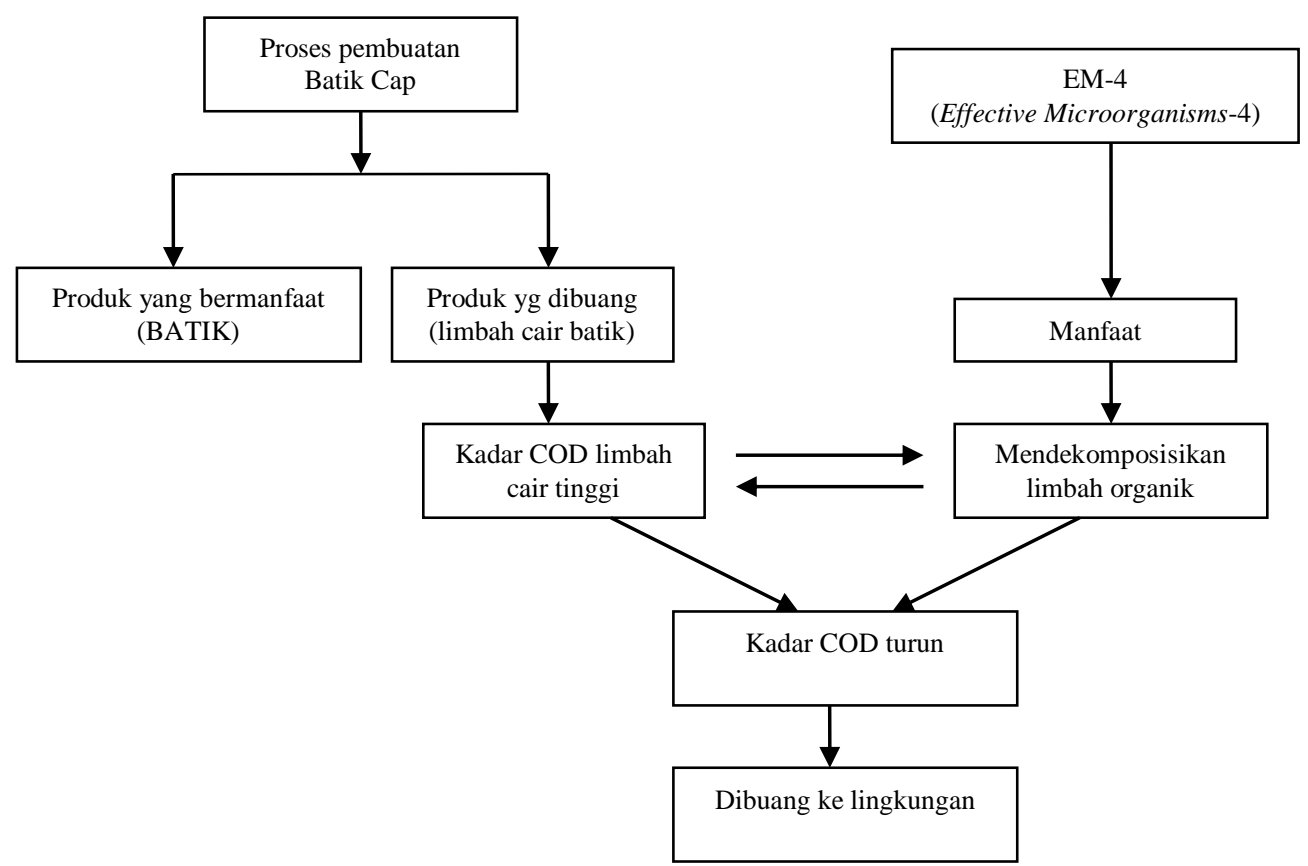

Gambar 1. Kerangka Pemikiran

\section{METODE PENELITIAN}

\subsection{Alat Dan Bahan}

3.1.1 Alat yang digunakan sebagai berikut; botol-botol inkubasi winkler (terbuat dari kaca) $250 \mathrm{ml}$, jerigen, gelas ukur $200 \mathrm{ml}$, labu ukur $50 \mathrm{ml}$, erlenmeyer $25 \mathrm{ml}$, pipet $10 \mathrm{ml}$, buret atau pengukur titrasi, termometer, pengukur $\mathrm{pH}$ elektrik, pemanas refluk, dan tabung refluk.
3.1.2 Bahan yang digunakan sebagai berikut; limbah cair batik cap, akuades, larutan FAS $250 \mathrm{ml}$ \{ FAS (Ferro Amonium Sulfat) $9,75 \mathrm{~g}+10 \mathrm{ml}$ akuades $+5 \mathrm{ml} \mathrm{H}_{2} \mathrm{SO}_{4}$ (asam sulfat), diencerkan mejadi $250 \mathrm{ml}$ dan diaduk\}, larutan $\mathrm{K}_{2} \mathrm{Cr}_{2} \mathrm{O}_{7}$ (kallium dikromat) 0,6125 g, diencerkan dengan akuades menjadi 50 $\mathrm{ml}$, larutan $\mathrm{H}_{2} \mathrm{SO}_{4}$ (asam sulfat) $90 \mathrm{ml}+$ $0,9 \quad \mathrm{~g} \mathrm{Ag}_{2} \mathrm{SO}_{4}$ ( silfersulfat) diaduk, 
$\mathrm{HgSO}_{4} \quad$ ( mercuri duasulfat) Indikator feroin, EM-4 (Effective Microorgandsms4).

\subsection{Populasi, Sampel, Sampling}

Populasi dalam penelitian adalah seluruh limbah batik di Kelurahan Simbang Wetan, Kabupaten Pekalongan. Sampel dan sampling, dalam penelitian ini adalah air limbah batik dari salah satu home industry batik.

\subsection{Rancangan Percobaan}

Rancangan percobaan pada penelitian ini menggunakan rancangan acak lengkap (RAL) pola faktorial yaitu dosis EM-4 (ml/l) dan lama inkubasi dengan menggunakan perlakuan; P0.2 = kontrol pada inkubasi 2 hari, $\mathrm{P} 0.3=$ kontrol pada inkubasi 3 hari, P1.1 = EM-4 $10 \mathrm{ml} / \mathrm{l}$ pada inkubasi 1 hari, P1.2 = EM$410 \mathrm{ml} / \mathrm{l}$ pada inkubasi 2 hari, P1.3 = EM-4 10 $\mathrm{ml} / \mathrm{l}$ pada inkubasi 3 hari,P2.1 = EM-4 $15 \mathrm{ml} / \mathrm{l}$ pada inkubasi 1 hari, P2.2 = EM-4 $15 \mathrm{ml} / \mathrm{l}$

pada inkubasi 2 hari, P2.3 = EM-4 $15 \mathrm{ml} / \mathrm{l}$ pada inkubasi 3 hari.

\subsection{Teknik Analisis Data}

Data hasil ekperimen isis secara deskriptif kuantitatif dalam bentuk statistik menggunakan analisis of variance (Anova) untuk menguji apakah ada beda pemberian EM-4 dalam berbagai konsentrasi dan lama inkubasi dalam penurunan kadar COD limbah batik cap.

\section{HASIL PENELITIAN DAN PEMBAHASAN} 4.1 . Data Hasil Penelitian

\subsubsection{Penurunan kadar COD}

Hasil perhitungan penurunan kadar COD limbah cair batik cap pada berbagai perlakuan dapat dilihat pada tabel 1 .

Tabel 1. Persentase Penurunan Kadar COD (Mg/l) Limbah Cair Batik Cap

\begin{tabular}{cccccc}
\hline Perlakuan & \multicolumn{3}{c}{ Ulangan } & $\begin{array}{c}\text { Rata-rata } \\
(\mathrm{mg} / \mathrm{l})\end{array}$ & $\begin{array}{c}\text { Persentase } \\
\text { Penurunan } \%\end{array}$ \\
\hline P0.1 & 5.972 & 5.940 & 5.876 & 5.929 & 0,00 \\
P0.2 & 4.471 & 4.407 & 4.375 & 4.417 & 0,00 \\
P0.3 & 5.588 & 5.492 & 5.429 & 5.503 & 0,00 \\
P1.1 & 2.586 & 2.267 & 2.203 & 2.352 & 60,33 \\
P1.2 & 2.618 & 2.299 & 2.203 & 2.373 & 46,27 \\
P1.3 & 2.552 & 2.459 & 2.395 & 2.468 & 55,15 \\
P2.1 & 255 & 223 & 191 & 223 & 96,24 \\
P2.2 & 287 & 255 & 223 & 255 & 94,23 \\
P2.3 & 1021 & 958 & 694 & 957 & 82,60 \\
\hline
\end{tabular}

Berdasarkan tabel di atas dapat diketahui bahwa kadar COD pada kontrol lebih besar daripada perlakuan, sedangkan pada masingmasing perlakuan. Semakin banyak penambahan EM-4 semakin kecil kadar COD. Rata-rata penurunan kadar COD setelah penambahan EM-4 adalah sebagai berikut; pada dosis $10 \mathrm{mg} / \mathrm{l}$, pada inkubasi hari pertama terjadi penurunan COD sebesar $3.577 \mathrm{mg} / \mathrm{l}$, atau $60,33 \%$. Pada inkubasi hari kedua terjadi penurunan COD $2.044 \mathrm{mg} / \mathrm{l}$, atau 46,27\%. Pada inkubasi hari ketiga terjadi penurunan
COD 3.468 mg/l. Pada dosis $15 \quad \mathrm{mg} / \mathrm{l}$ menunjukkan penurunan COD pada inkubasi hari pertama sebesar $5.706 \mathrm{mg} / \mathrm{l}$, atau 96,24 \%, pada inkubasi hari kedua terjadi penurunan COD sebesar $4.162 \mathrm{mg} / \mathrm{l}$, atau 94,23\%, pada inkubasi hari ketiga terjadi penurunan COD sebesar $4.546 \mathrm{mg} / \mathrm{l}$, atau 82,60 \%. Dari tabel 1, kemudian dilanjutkan dari uji Anova dua jalur untuk mengetahui apakah ketiga populasi mempunyai rata-rata (mean) yang sama ataukah berbeda. 
Tabel 2. Daftar Analisis Ragam Anova pada Limbah Cair Batik Cap

\begin{tabular}{lccccc}
\hline $\begin{array}{l}\text { Sumber } \\
\text { Keragaman }\end{array}$ & $\mathrm{db}$ & $\mathrm{JK}$ & $\mathrm{KT}$ & $\mathrm{F}$ & $\begin{array}{c}\mathrm{F} 5 \\
\%\end{array}$ \\
\hline Perlakuan & 8 & 109939144,000 & 13742393,000 & 1099,323 & 2,51 \\
Dosis & 2 & 105241094,000 & 52620547,000 & 4209,382 & 3,55 \\
Waktu & 2 & 1944016,667 & 972008,333 & 77,756 & 3,55 \\
Interaksi & 4 & 2754033,333 & 688508,333 & 55,077 & 2,93 \\
Galat & 18 & 225014,000 & 12500,778 & & \\
Total & 26 & 110164158,000 & & & \\
\hline
\end{tabular}

\subsection{2 pH dan Suhu Air Limbah Batik Cap.}

Sebelum penghitungan kadar COD, dilakukan terlebih dahulu pemeriksaan $\mathrm{pH}$ dan suhu air limbah batik cap pada kontrol dan berbagai perlakuan (tabel 2).

Tabel 3. Hasil Pengukuran pH dan Suhu Air Limbah Batik Cap pada Kontrol dan Berbagai Perlakuan

\begin{tabular}{ccccc}
\hline Parameter & $\begin{array}{c}\text { Lama inkubasi } \\
\text { (hari) }\end{array}$ & Kontrol & $\begin{array}{c}\text { EM-4 Dosis 10 } \\
\mathrm{ml} / \mathrm{l}\end{array}$ & $\begin{array}{c}\text { EM-4 Dosis 15 } \\
\mathrm{ml} / 1\end{array}$ \\
\hline \multirow{3}{*}{ Suhu $\left({ }^{0} \mathrm{C}\right)$} & 1 & 28 & 27 & 27 \\
& 2 & 28 & 27 & 27 \\
\hline \multirow{3}{*}{$\mathrm{PH}$} & 3 & 29 & 28 & 28 \\
\hline & 1 & 7,05 & 6,70 & 6,55 \\
& 2 & 8,80 & 720 & 7,00 \\
& 3 & 9,00 & 8,50 & 8,10 \\
\hline
\end{tabular}

Berdasarkan tabel di atas dapat diketahui bahwa kadar $\mathrm{pH}$ pada kontrol lebih besar dari pada $\mathrm{pH}$ pada berbagai perlakuan. Begitu pula dengan suhu, pada kontrol lebih besar daripada berbagai perlakuan.

\subsection{Pembahasan}

\subsubsection{Kadar COD}

Berdasarkan hasil uji Anova dua jalur (Tabel 2), menunjukkan bahwa pada taraf nyata $5 \%$ terlihat ada beda nyata perlakuan EM-4 yang ditunjukkan dengan harga $\mathrm{F}$ hitung sebesar 1099,323 > F tabel sebesar 2,51. Hal ini menunjukkan bahwa pemberian dosis EM-4 yang berbeda berpengaruh nyata terhadap penurunan kadar COD limbah cair batik cap. Untuk perlakuan waktu inkubasi ditunjukkan dengan harga $\mathrm{F}$ hitung sebesar 77,756 > F tabel sebesar 3,55.

Hal ini menunjukkan bahwa lama waktu inkubasi berpengaruh nyata terhadap penurunan COD limbah batik cap, sedangkan untuk interaksi EM-4 dengan waktu inkubasi ditunjukan dengan harga $\mathrm{F}$ hitung sebesar 55,077 > F tabel 2,93 yang menunjukkan bahwa perlakuan dosis dan lama waktu inkubasi berpengaruh nyata terhadap penurunan kadar COD limbah batik cap, sedangkan pada grafik menggambarkan adanya penurunan pada setiap pemberian perlakuan EM-4. Wardana (1995) menyatakan bahwa salah satu indikator pencemar air yang merupakan pencemar utama limbah batik cap adalah COD. COD atau kebutuhan oksigen kimia adalah jumlah oksigen yang diperlukan 
agar bahan buangan yang ada di dalam air dapat teroksidasi melalui reaksi kimia. Dalam hal ini bahan buangan organik akan dioksidasi oleh callium bichromat menjadi gas $\mathrm{CO}_{2}$ dan serta sejumlah ion krom. Callium bichromat atau $\mathrm{K}_{2}$ digunakan sebagai sumber oksigen (oxydizing agent). Hal ini juga dipertegas pada penelitian Ernik Indarwati (2004), pada EM-4 dengan dosis $14 \mathrm{ml} / \mathrm{l}$ merupakan dosis yang paling baik dalam menurunkan kadar COD limbah batik. Kegiatan industri merupakan salah satu penyebab utama terjadinya pencemaran air. Hal ini terjadi karena kurangnya bahkan tidak adanya pengelolaan limbah yang memadai. Bahan-bahan pencemar, terutama bahan buangan padat, bahan buangan organik, bahan buangan anorganik, bahan buangan olahan bahan makanan, dan lain sebagainya (Wardhana, 1995). Berdasarkan Tabel 1, dapat digambarkan grafik hubungan kadar COD dengan perlakuan (penambahan EM-4 dan lama inkubasi).

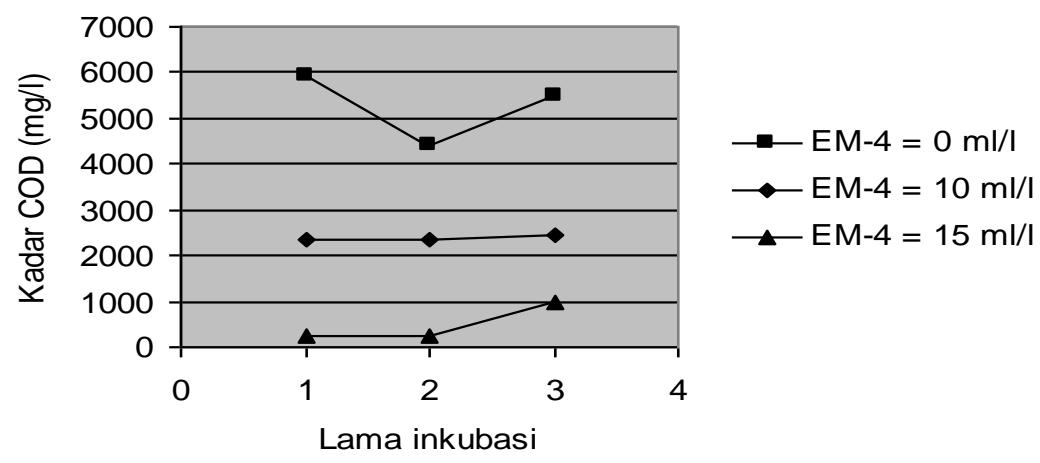

Gambar 2. Grafik Hubungan Kadar COD (mg/l) dengan Berbagai Penambahan EM-4 dan Lama Inkubasi

Berdasarkan pada grafik di atas dapat diketahui bahwa semakin banyak penambahan EM-4 semakin kecil kadar COD. Berdasarkan analisis data, dosis EM-4 yang efektif untuk menurunkan kadar COD yang paling tinggi adalah dosis $15 \mathrm{ml} / \mathrm{l}$, pada inkubasi hari pertama yaitu mampu menurunkan kadar COD $5.929 \mathrm{mg} / \mathrm{l}$ menjadi $223 \mathrm{mg} / \mathrm{l}$, sehingga terhitung penurunan sebesar $5.706 \mathrm{mg} / \mathrm{l}$ atau $96,24 \%$. Pada dosis $15 \mathrm{ml} / \mathrm{l}$ dengan inkubasi hari kedua yaitu mampu menurunkan kadar COD $4.417 \mathrm{mg} / \mathrm{l}$ menjadi $255 \mathrm{mg} / \mathrm{l}$, sehingga terhitung penurunan sebesar $4.162 \mathrm{mg} / \mathrm{l}$ atau 94,23\% . Jadi kadar COD termasuk golongan dua dan memenuhi syarat pada baku mutu limbah cair, sehingga limbah aman untuk dibuang ke suatu badan air. Waktu inkubasi yang paling efektif untuk menurunkan kadar COD adalah inkubasi pada hari pertama.
Penurunan kadar COD ini disebabkan oleh adanya penambahan EM-4, karena dalam EM4 tersebut terdapat bakteri yang merupakan organisme utama dalam penanganan limbah secara hayati. Dalam hal ini bakteri asam laktat sebagai salah satu penyusun komposisi EM-4 memiliki peran yaitu menggunakan bahan organik sebagai sumber energi dan karbon. Energi yang dihasilkan melalui proses perombakan selain digunakan untuk aktivitas katabolisme juga digunakan untuk biosintesa, sehingga selama ketersediaan nutrien terjamin maka jumlah sel bakteri akan meningkat (Indriani, 1999). Pada perlakuan dosis EM-4 $15 \mathrm{ml} / \mathrm{l}$ dengan inkubasi hari ketiga yaitu mampu menurunkan kadar COD 5.503 mg/l menjadi $957 \mathrm{mg} / \mathrm{l}$, sehingga terhitung penurunan sebesar $4.546 \mathrm{mg} / \mathrm{l}$ atau $82,60 \%$. Ini masih menunjukkan kadar COD masih 
tinggi. Hal ini disebabkan waktu inkubasi terlalu lama, sehingga bakteri penghasil asam laktat apabila sudah sampai pada titik kejenuhan bisa menyebabkan naiknya kadar COD. Berdasarkan keputusan Menteri Negara Lingkungan Hidup No: KEP-03/MENKLH/II/ 1991 tentang standar baku mutu limbah cair bagi kegiatan yang sudah beroperasi, baku mutu air limbah industri untuk parameter COD sebagai berikut; golongan I adalah $40 \mathrm{mg} / \mathrm{l}$, golongan II adalah $100 \mathrm{mg} / \mathrm{l}$, golongan III adalah $300 \mathrm{mg} / \mathrm{l}$ dan golongan IV adalah 600 $\mathrm{mg} / \mathrm{l}$. Data yang ada menunjukkan bahwa kadar COD yang terkandung dalam limbah cair batik cap dengan dosis EM-4 yang paling efektif $15 \mathrm{ml} / \mathrm{l}$ dan inkubasi yang efektif pada hari pertama adalah $223 \mathrm{mg} / \mathrm{l}$ termasuk golongan II pada baku mutu limbah cair. Jadi limbah tersebut termasuk aman jika dibuang ke badan air.

\subsection{2 pH (Potensial Hidrogen)}

Berdasarkan (Tabel 3) dapat diketahui bahwa $\mathrm{pH}$ air limbah batik untuk kontrol pada inkubasi hari pertama adalah 7,05 dan hari kedua adalah 8,80 sedangkan hari ketiga adalah 9,00 yang bersifat basa. Setelah pemberian EM-4 $10 \mathrm{ml} / \mathrm{l} \mathrm{pH}$ pada inkubasi hari pertama adalah 6,70 (terjadi penurunan $\mathrm{pH}$ sebesar 0,35). Pada inkubasi hari kedua $\mathrm{pH}$ 7,20 (terjadi penurunan $\mathrm{pH}$ sebesar 1,6 ), dan pada inkubasi hari ketiga adalah 8,50 yang berarti masih basa (terjadi penurunan $\mathrm{pH}$ sebesar 0,50). Pada pemberian EM-4 $15 \mathrm{ml} / \mathrm{l}$ $\mathrm{pH}$ pada inkubasi hari pertama adalah 6,55 (terjadi penurunan $\mathrm{pH}$ sebesar 0,5), pada inkubasi hari kedua adalah 7,00 (terjadi penurunan $\mathrm{pH}$ sebesar 1,8 ), pada inkubasi hari ketiga adalah 8,10 (terjadi penurunan $\mathrm{pH}$ sebesar 0,9) yang berarti masih basa, tetapi terjadi penurunan $\mathrm{pH}$ yang mendekati $\mathrm{pH}$ sesuai keputusan menteri negara KLH, No. KEP-03/MENKLH/11/1991. Potensial Hidrogen $(\mathrm{pH})$ yang optimal pada perlakuan adalah EM-4 pada dosis $15 \mathrm{ml} / \mathrm{l}$ dan pada inkubasi satu hari, karena pada perlakuan ini terhitung $\mathrm{pH}$ paling rendah yaitu 6,55 . Hal ini dimugkinkan salah satu komponen dari EM-4 yaitu Lactobacillus merupakan mikroorganisme penghasil asam sehingga kebasaan limbah menurun. Jika dibanding dengan surat keputusan menteri negara KLH, No. KEP-03/MENKLH/11/1991, pH 6-9 untuk air limbah setelah penambahan EM-4 telah memenuhi standar yang telah ditentukan. Udin Djabu (1991), menyatakan bahwa potensial hidrogen 6,5-8,5 merupakan batasan yang diperbolehkan dalam air buangan.

\subsubsection{Suhu}

Berdasarkan (Tabel 3) dapat diketahui suhu air limbah batik cap pada inkubasi hari pertama dan hari kedua, pada kontrol rata-rata $28^{\circ} \mathrm{C}$ sedangkan suhu pada perlakuan rata-rata $27{ }^{\circ} \mathrm{C}$, suhu pada inkubasi hari ketiga, pada kontrol adalah $29{ }^{\circ} \mathrm{C}$ dan pada perlakuan ratarata $28{ }^{\circ} \mathrm{C}$. Suhu yang optimal pada inkubasi hari pertama dan hari kedua, karena suhu pada inkubasi hari pertama dan hari kedua adalah sama. Hal ini dipertegas sesuai dengan golongan satu pada baku mutu air limbah.

Wardhana (1995), apabila air limbah yang panas langsung dibuang ke sungai maka air sungai akan menjadi panas. Oksigen yang terlarut di dalam air berasal dari udara yang secara lambat terdifusi ke dalam alam. Semakin tinggi kenaikan suhu air makin sedikit kandungan oksigen yang terlarut di dalamnya.

\section{KESIMPULAN}

Berdasarkan hasil penelitian "Efektivitas EM-4 dan Lama Inubasi Dalam Menurunkan Kadar COD Limbah Cair Batik Cap di Kelurahan Simbang Wetan KotaPekalongan“ dapat disimpulkan sebagai berikut ;

1. Penambahan EM-4 dalam limbah cair batik cap dengan dosis $0 \mathrm{ml} / \mathrm{l}, 10 \mathrm{ml} / \mathrm{l}, 15 \mathrm{ml} / \mathrm{l}$ berpengaruh nyata terhadap penurunan kadar COD. 
2. Lama inkubasi satu hari, dua hari dan tiga hari berpengaruh nyata terhadap penurunan kadar COD pada limbah cair batik cap.

3. Dosis EM-4 yang paling efektif untuk menurunkan kadar COD limbah cair batik cap adalah $15 \mathrm{ml} / \mathrm{l}$, yaitu mampu menurunkan kadar COD sebesar 96,28\% dan waktu inkubasi yang efektif adalah satu hari.

\section{Saran}

1. Perlunya pengolahan limbah batik dengan EM-4 sebelum limbah dibuang ke lingkungan.

2. Perlunya penelitian lanjutan yang terkait tentang pengelolaan limbah batik yang lebih efektif dan murah.

\section{DAFTAR PUSTAKA}

Achillas, C., N. Moussiopoulos., A. Karagiannidis., G. Banians., and G. Perkoulidis. 2013. The Use of Multicriteria Decision Analysis to Tackle Waste Management Problems. Review Waste Management and Research. 31 (2): 115-129.

Darsono, V. 1995. Pengantar Ilmu Lingkungan. Universitas Atmajaya, Yogyakarta.

Djabu, U. 1991. Pedoman bidang studi Pembuangan Tinja dan Air Limbah Pada Institusi Pendidikan Sanitasi Kesehatan Lingkungan. Depkes RI Pusat Pendidikan Tenaga Kesehatan, Jakarta.

Estikarini, H.D., M. Hadiwidodo., dan V. Luvita. 2016. Penurunan Kadar COD dan TTS Pada Limbah Tekstil dengan Metode Ozonasi. Jurnal Teknik Lingkungan, 5 (1); 1-11.

Fardiaz, S. 1992. Polusi Air dan Udara. Kanisius, Jakarta.

Indarwati, E. 2004. Pengaruh Pemberian EM-4 Terhadap Penurunan Kadar COD Limbah Cair Batik di Desa Pilang, Kecamatan, Masaran, Kabupaten Sragen. Skripsi
Fakultas Kesehatan Ilmu Lingkungan. Universitas Muhammadiyah Surakarta. Surakarta.

Indriani,Y.H. 1999. Membuat Kompos secara Kilat. Penebar Swadaya. Jakarta.

Islamiati, D., Y. Hanani., Darundiati., dan N.A. Dewanti. 2018. Studi Penurunan kadar COD (Chemical Oxygen Demand) Menggunakan Ferri Klorida $\left(\mathrm{FeCl}_{3}\right)$ Pada Limbah Cair Tapioka di Desa Ngemplak Margoyoso Pati. Jurnal Kesehatan Masyarakat, 6 (6); 2356-3346.

Meriatna., S., dan A. Fahri. 2018. Pengaruh Waktu Fermentasi dan Volume Bio Aktivitor EM-4 (Effective Microorganisme) Pada Pembuatan Pupuk Organik Cair (POC) dari Limbah BuahBuahan. Jurnal Teknik Kimia Unimal, 7 (1); 13-29.

Nasir, M., dan Fatkhurohman. 2010. Model Pembentukan Kesadaran Kolektif terhadap Manajemen Lingkungan Pengusaha Kecil Tahu-Tempe di Solo. Laporan hibah bersaing Dikti.

Prasetya, Y. 2001. Efektivitas EM-4 Dalam Menurunkan Kadar TSS Limbah cair Industri Tahu. Penelitian Fakultas Kesehatan Masyarakat Undip. Universitas Diponegoro, Semarang.

Rahmat, B., dan A. Mallongi. 2018. Studi Karakteristik dan Kualitas BOD dan COD Limbah Cair Rumah SakitUmum Daerah LantoDG Pasewang Kabupaten Jeneponto. Jurnal Nasional Ilmu Kesehatan, 1 (6); 1-19.

Setiawati, P. 2004. Kupas Tuntas Teknik Proses Membatik. Absolut, Yogyakarta.

Setiyani, O. 2000. Pengolahan Limbah Organik Dengan EM Sebagai Bahan Baku Kompos. Hand Out Materi Perkuliahan Teknologi Tepat Guna Fakultas Kesehatan masyarakat Undip. Universitas Diponegoro, Semarang.

Slamet, Y.S. 1996. Kesehatan Lingkungan. Universitas Gajah Mada 
Sri Undiyati, 2003. Efektivitas EM-4 (Effective microorganism-4) dan Lama Inkubasi Dalam Menurunkan COD Limbah Cair Tahu di Kelurahan Mojosongo Surakarta. Skripsi Fakultas Keguruan dan Ilmu Pendidikan Jurusan Biologi. Universitas Muhammadiyah Surakarta, Surakarta.

Sovia, 1., Y. Achdiani., dan I. Widyawati. 2016. Penguasaan Pengetahuan Pembuatan Batik Cap pada Peserta Didik SMKN 14 Bandung. Jurnal Familyedu, 2 (1); 15-20.

Wardana., dan A. Wisnu. 1995. Dampak Pencemaran Lingkungan. Andi Offset, Yogyakarta.

Xue, M., J.Li., dan Xu, Z. 2013. Management Stategies on the Industrializatin Road of State of the art Techmnologies for EWaste Recycling: The Case Study of ElectrostaticSeparation: A Review Waste Management and Research, 31 (2): 130140.

Yuliastuti, R., dan C.B. Handaru.2017. Efektifitas Pengolahan Limbah Cair Industri Asbes Menggunakan Flokulan dan Adsorben. Jurnal Teknologi Proses Dan Inovasi Industri, 2 (2): 77-83. 